AperTO - Archivio Istituzionale Open Access dell'Università di Torino

MicroRNA let-7a Modifies the Effect of Self-Renewal Gene HIWI on Patient Survival of Epithelial Ovarian Cancer.

This is a pre print version of the following article:

Original Citation:

Availability:

This version is available http://hdl.handle.net/2318/1508417

since 2016-06-10T13:11:04Z

Published version:

DOI: $10.1002 / \mathrm{mc} .22285$

Terms of use:

Open Access

Anyone can freely access the full text of works made available as "Open Access". Works made available under a Creative Commons license can be used according to the terms and conditions of said license. Use of all other works requires consent of the right holder (author or publisher) if not exempted from copyright protection by the applicable law. 


\title{
MicroRNA let-7a Modifies the Effect of Self-renewal Gene HIWI on Patient Survival of Epithelial Ovarian Cancer
}

\author{
Lingeng $\mathrm{Lu}^{1, *}$, Dionyssios Katsaros ${ }^{2}$, Harvey A Risch ${ }^{1}$, Emilie Marion Canuto ${ }^{2}$, \\ Nicoletta Biglia ${ }^{4}$, Herbert $\mathrm{Yu}^{1,3}$
}

1. Department of Chronic Disease Epidemiology, School of Public Health, School of Medicine, Yale Cancer Center, Yale University, New Haven, CT 06520-8034, USA

2. Department of Surgical Science, A O Città della Salute e della Scienza di Torino, S.Anna Hospital, 10126 Turin, Italy

3. Cancer Epidemiology Program, University of Hawaii Cancer Center, Honolulu, HI 96813, USA

4. Department of Surgical Science, Division of Obstetrics and Gynecology, University of Torino, Mauriziano Hospital, 10128 Turin, Italy

*Corresponding Author:

Dr. Lingeng Lu, Department of Chronic Disease Epidemiology, School of Public Health, School of Medicine, Yale University, 60 College Street, New Haven, CT 06520-8034, USA. Phone: 203-737-6812, Fax: 203-785-2207, Email:

lingeng.lu@yale.edu

Running title: $H I W I$ and let-7a interplay in ovarian cancer prognosis

Key Words: Epithelial ovarian cancer, piwi-like RNA-mediated gene silencing 1

Abstract: 248 words, Text: 3451 words.

1 figure, 5 tables 


\section{Abstract}

2 Aberrant expressions of self-renewal gene HIWI and microRNA let-7a are in epithelial

3 ovarian cancer (EOC). A U-shape association between HIWI expression and overall

4 survival is seen in several human cancers but unknown in EOC. HIWI physically binds

5 let-7a, but the clinical relevance of this interaction is yet to be addressed. Here we

6 analyzed $H I W I$ and let-7a expressions in 211 primary EOC tissues using quantitative

7 reverse transcription PCR to investigate $H I W I$ and its interaction with let-7a in the

8 prognostic significance of EOC. Associations of $H I W I$ and its interaction with miRNA

9 let-7a with patient survival were analyzed using the Kaplan-Meier survival curves and

10 Cox proportional hazard regression models. Kaplan-Meier survival curves showed that

11 patients with medium $H I W I$ had poorer overall survival than those with low or high

12 HIWI. An $89 \%$ increased death risk $(\mathrm{HR}=1.89,95 \%$ CI: $1.29-2.98)$ was observed in

13 the medium HIWI group in multivariate Cox proportional hazard regression analyses.

14 Among patients with high let-7a expression, those with medium HIWI had an increased

15 risk of death compared to those with low HIWI (HR $=2.62,95 \%$ CI: $1.30-5.30)$,

16 whereas among those with low let-7a, no significant association between HIWI

17 expression and overall survival was observed ( $\mathrm{HR}=1.63,95 \% \mathrm{CI}: 0.86-3.08)$.

18 Moreover, HIWI expression also affected chemotherapy response. The results suggested

19 that miRNA let-7a could modify the effect of $H I W I$ expression on patient survival of

20 EOC, expanding our understanding of the clinical relevance of $H I W I$ and let-7a

21 interaction in EOC prognosis. 


\section{Introduction}

2 HIWI (also known as piwi-like RNA-mediated gene silencing 1, PIWIL1), located on

3 chromosome 12q14.33, is a member of the P-element induced wimpy testis (PIWI) gene

4 family in humans [1]. This family is evolutionarily conserved across species; their

5 encoded-proteins are highly homologous, particularly in the carboxy-terminus [1]. The

6 HIWI is a ribonucleoprotein in the length of 861 amino acids, which contains a N-

7 terminal PIWI/Argonaute/Zwille (PAZ) domain and a PIWI domain at the carboxy-

8 terminus [2-4]. The PAZ domain binds to single-stranded small RNA, and the PIWI

9 domain functions as an RNase $\mathrm{H}$ endonuclease cleaving target RNA complementarily

10 bound to small RNA [4-6]. The involvement of HIWI proteins in the regulation of gene

11 expression is through their interacting partners of small non-coding RNAs such as

12 namely PIWI-associated RNAs (piRNAs) [7]. Nuclear HIWI controls retrotransposon

13 silencing via affecting DNA methylation [8-10]. Recently, Sequencing results of

14 Immunoprecipitation (IP) against HIWI show that HIWI interacts with miRNAs

15 including let-7a in fining gene expression [11]. Moreover, it has also been reported that

16 HIWI can be a partner interacting with Dicer, a key RNase III endonuclease in miRNA

17 maturation [12-14]. These findings suggest HIWI is also localized in cytoplasm and

18 may participate in the role of miRNAs in gene regulation. The HIWI gene is expressed

19 in hematopoietic stem cells and germ cells but not in differentiated cells. It has been

20 evidenced that HIWI plays an important role in maintaining stem cell renewal

$21[1,7,15,16]$. In the PIWI mutant models, germline stem cell asymmetric divisions cannot

22 be functionally processed in both male and female flies, leading to a loss of germline

23 stem cells and a reduced number of eggs and sperms during oogenesis or 
1 spermatogenesis $[7,17]$. In healthy women, those with age younger than 50 years old

2 express HIWI in ovary tissues [18].

3 Aberrant HIWI expression is associated with tumorigenesis and with cancer patient

4 survival. Over-expressed HIWI has been observed in seminomas testicular tumors but

5 not in nonsemnomatous, spermatocytic seminomas and somatic types [1,19]. A large

6 number of gastric cancers show increased HIWI expression in comparison to normal

7 tissues, and HIWI has been involved in the proliferation of gastric cancer cells [20].

8 Both U-shape and linear associations between HIWI expression levels and cancer

9 patient survival have been observed. Compared to moderate expression, both low and

10 high HIWI expression were reported to be associated with increased death in patients

11 with soft-tissue sarcoma, suggesting that HIWI may have biphasic effects on tumor

12 progression [21,22]. Recently, Grochola et al. reported that HIWI expression increased

13 pancreatic cancer-related death but in a male-specific manner [23]. Prognostic value of

14 HIWI has been shown in several human solid tumors including hepatocellular

15 carcinoma [24], colorectal cancer [25], glioma [26], and esophageal carcinoma [27].

16 Very recently, it has also been shown that the expression of HIWI was significantly

17 higher in epithelial ovarian cancer than in normal ovaries and benign tumors, while

18 enforced overexpression of $H I W I$ in SKOV3 ovarian cancer cell line led to reduced

19 metastatic capacity [18], suggesting moderate HIWI expression may associate with

20 tumor development and progression in ovarian cancer. However, whether HIWI

21 expression has prognostic value in ovarian cancer is yet to be investigated. 
1 MicroRNA let-7a is one member of let-7 family, which is one well-characterized

2 miRNA in controlling gene expression, and plays important roles in cell proliferation,

3 differentiation, apoptosis and metabolism [28-30]. Dysregulated let-7a has been

4 reported in different types of human cancer [31-34], and associates with cell

5 proliferation, chemotherapy response, and patient survival [35-37]. Moreover, the

6 involvement of let-7a has been demonstrated in stemness [38-40]. Our previous study

7 also showed that let-7a was associated with epithelial ovarian cancer survival [37].

8 Given that cytoplasmic HIWI protein can interact with let-7a directly [11] or indirectly

9 through miRNA maturation-associated protein Dicer, which could form a negative

10 feedback loop with let-7a [41], and that both HIWI and let-7a are involved in the

11 maintenance of stem cells $[1,7,15,16,42]$, we speculate that HIWI and let-7a may

12 orchestrate in executing biological functions. Thus, the purposes of this study were to

13 determine HIWI expression and its interaction with let-7a in the prognosis of epithelial

14 ovarian cancer.

16 Materials and Methods

$17 \quad$ Patients and tumor samples

18 In this study, a written informed consent was obtained from each individual of the

19 participants, and all subjects in this study were de-identified for the sake of participants'

20 privacy. With the approval of the University's ethical review committee, 211 women

21 diagnosed with epithelial ovarian cancer were enrolled between October 1991 and

22 February 2000 in the Department of Gynecology and Obstetrics at University of Turin

23 in Italy. Fresh tumor tissues were collected for the study at surgery. Disease stage and 
1 tumor grade were determined for each patient according to the International Federation

2 of Gynecology and Obstetrics Classification (FIGO) and WHO criteria [43,44]. Most of

3 the patients received standard post-operative chemotherapy after cytoreduction surgery

4 and were subsequently followed up for disease progression until June 2001. Median

5 follow-up time was 31 months, ranging from 0.6 to 114 months.

6

7 There were four categories of treatment response defined in the study. The definition is

8 as follows: (a) complete response: resolution of all evidence of disease for at least a

9 month, (b) partial response: a decrease of $\geq 50 \%$ in the product of the diameters

10 (maximum and minimum) of all measurable lesions without the development of new

11 lesions for at least a month, (c) stable disease: a decrease of $<50 \%$ or an increase of

$12<25 \%$ in the product of the diameters of all measurable lesion, and (d) progressive

13 disease: an increase of $\geq 25 \%$ in the product of the diameters of all measurable lesions or

14 the development of new lesions. Of the 176 patients with available information on

15 chemotherapy treatment response, $128(72.7 \%)$ who had complete response was

16 considered 'Yes' response in data analysis, while 48 (27.3\%) who were in the other

17 three categories were grouped as 'No' response, which included 36 with partial

18 response, 4 with stable disease, and 8 with progressive disease.

20 Analysis of HIWI and let-7a expression

21 All tumor samples were examined by two independent pathologists, and the specimens

22 which contained 80-90\% tumor cells were used in this study. Total RNAs extracted

23 from the tumor samples were used as templates to make cDNA using the Cloned AMV 
1 First-Strand cDNA Synthesis kit (Invitrogen ${ }^{\mathrm{TM}}$, Carlsbad, CA). The primers for HIWI

2 and small nucleolar RNA RNU48 (used for normalization) were designed based on

3 sequences in Genbank (accession number AB274731 for HIWI and X96648 for

4 RNU48). The primer sequences for HIWI and RNU48 are: HIWI-forward, 5'- CCT GGC

5 TTC ACT ACT TCC ATC C; HIWI-reverse, 5'- ACG TCA GTG CAG AGC ATG

6 ATG; RNU48-forward, 5'AGTGATGATGACCCCAGGTAACTC, and RNU48-

7 reverse, 5'- CTG CGG TGA TGG CAT CAG. Real-time PCR was performed to analyze

8 HIWI expression using the Chromo $4^{\mathrm{TM}}$ Real-time PCR System (MJ Research Inc.,

9 Waltham, MA). In the PCR reaction $(20 \mu \mathrm{l}), 2 \mu \mathrm{l}$ of cDNA template was mixed with 10

$10 \mu \mathrm{l}$ of $2 \times$ Power SYBR $^{\circledR}$ Green PCR master mix (Applied Biosystems, Foster City, CA)

11 and each pair of primers, at final concentrations of $100 \mathrm{nM}$ for both $H I W I$ and $R N U 48$.

12 PCR amplification included initial incubation at $50^{\circ} \mathrm{C}$ for 2 minutes, denaturing at $95^{\circ} \mathrm{C}$

13 for 10 minutes, and 40 cycles of denaturing at $95^{\circ} \mathrm{C}$ for 15 seconds and annealing at

$1460^{\circ} \mathrm{C}$ for one minute. Melting curves were analyzed after each run to verify the size of

15 PCR product.

16 Analysis of let-7a expression in tumor tissue was performed using Taqman ${ }^{\circledR}$ microRNA

17 assay (Applied Biosystems), in which the preparation of miRNA cDNA was made first

18 using a stem-loop method, following the manufacturer's instruction as described in our

19 previous report [45]. Briefly, levels of let-7a and RNU48 (an internal control for

20 normalization) expression in the samples were determined with the Taqman ${ }^{\circledR}$ miRNA

21 assay (Applied Biosystems) using the Chromo4 Real-time PCR System. In the PCR

22 reaction $(15 \mu \mathrm{l}), 0.3 \mu \mathrm{l}$ of cDNA template was mixed with $7.5 \mu \mathrm{l}$ of $2 \times$ Taqman $^{\circledR}$

23 Universal PCR master mix (Applied Biosystems), $0.75 \mu 1$ of $20 \times$ probe/primers 
1 (Applied Biosystems) of either let-7a or RNU48, and water. The PCR amplification

2 conditions were the same as for the quantification of HIWI gene in this study.

3 Each sample was analyzed in duplicate, and the analysis was repeated for those with

4 CV above $5 \%$.

5

$6 \quad$ Statistical analysis

$7 \quad$ HIWI and let-7a expression was quantified as an expression index (EI), which was

8 calculated based on the formula $1000 \times 2^{(-\Delta \mathrm{Ct})}$, where $\Delta \mathrm{Ct}=\mathrm{Ct}_{\text {target gene }}-\mathrm{Ct}_{\mathrm{RNU} 48}$. To

9 analyze HIWI's associations with disease features and patient survival, the EI values

10 were grouped into 3 categories, low, medium and high, which were classified as

11 undetectable expression, detectable expression below median and detectable expression

12 equal to or above median, respectively. Let-7a was classified into two groups, low and

13 high, based on the median of let-7a expression distribution as the cutoff when the

14 interaction analysis was performed. Associations between HIWI expression and

15 clinicopathologic factors were analyzed by Chi-square statistic or Fisher's exact statistic

16 as appropriate. Survival analysis was performed to assess associations of $H I W I$

17 expression with risks of disease progression and death. Cox proportional hazards

18 regression and Kaplan-Meier survival curves were employed for the survival analyses.

19 Proportional hazards assumption was also tested in Cox proportional hazards

20 regression. All statistical analyses were performed using SAS version 9.2 (SAS

21 Institute, Cary, NC). All p-values are two-sided. Significant values are shown in bold.

22

23 


\section{$1 \quad$ Results}

2

3 Clinical and pathological characteristics of patients

4 Clinical and pathological features of the 211 participants enrolled in this study were

5 shown in Table 1. These patients underwent surgery at ages between 26 to 82 years,

6 and the median age was 58 years. Based on the International Federation of Gynecology

7 and Obstetrics Classification [43], 52 patients were diagnosed with stage I disease

8 (24.6\%), 12 stage II (5.7\%), 133 stage III (63.0\%), and 14 stage IV (6.6\%). Tumor

9 grade and histology were determined according to the WHO guidelines [44]. Thirty-

10 four (16.1\%) were grade 1 tumors, $40(19.0 \%)$ grade 2 and 137(64.9\%) grade 3.

11 Eighty-five (40.3\%) patients had serous tumors, and 126 patients had non-serous tumors

12 which included $16(7.6 \%)$ clear cell, $41(19.4 \%)$ endometrial, $18(8.5 \%)$ mucinous, 14

$13(6.6 \%)$ müllerian, 1 other $(0.5 \%)$ and $36(17.1 \%)$ undifferentiated histology. Surgical

14 debulking was performed on all the patients. Optimal debulking results were achieved

15 in $108(51.9 \%)$ patients, and $100(48.1 \%)$ had suboptimal outcomes. Ninety-one

16 patients (44.0\%) had no residual tumor, and $116(56.0 \%)$ had a residual tumor size

17 greater than 0.

18

19

20

21 Of 211 samples, 82 (38.9\%), over a third, had undetectable expression of $H I W I$, and

22129 had detectable expression with an average EI of 0.32, ranging from 0.02 to 4.86

$23\left(5^{\text {th }}-95^{\text {th }}\right.$ percentiles $)$. To investigate the impact of HIWI expression on prognosis of

24 ovarian cancer, we classified patients based on their HIWI expression into three groups,

25 low, medium and high, using the $\mathrm{EI}=0$ (undetectable), $>0$ to $<0.32$, and $\geq 0.32$ as 
1 cutoffs. The numbers of patients in these groups were 82, 65 and 64, respectively.

2 Kaplan-Meier survival curves showed that patients with low and high HIWI did not

3 have substantial differences in progression-free or overall survival, but did have more

4 favorable prognosis than those with medium HIWI expression (data not shown). Based

5 on this finding and U-shaped associations with death observed elsewhere [21-23], we

6 combined the low and high groups together, and compared their survival outcomes with

7 those with medium HIWI expression. Kaplan-Meier survival curves showed that

8 patients with medium expression had worse overall survival $(\mathrm{p}=0.025)($ Figure 1$)$.

9 However, disease progression-free survival was not different by $H I W I$ expression $(\mathrm{p}=$ 10 0.200) (data not shown).

11

12 To confirm the results of Kaplan-Meier analysis and to adjust for potential confounding

13 factors, we further analyzed the data with the Cox proportional hazards regression.

14 Proportional hazards assumption test for HIWI expression did not show significance (p

$15=0.59)$. The results of univariate and multivariate analyses were shown in Table 2. Here

16 too, medium HIWI expression was significantly associated with elevated risk for death

17 in both univariate and multivariate analyses. After adjustment for patient age at surgery,

18 disease stage, tumor grade, residual tumor size, histological type and chemotherapy

19 status, the association remained significant. The adjusted hazard ratio (HR) was 1.89

20 (95\% CI: $1.29-2.98)$ for high or low HIWI expression compared to medium

21 expression. In addition, disease stage and residual tumor size showed positive

22 associations with the risk of death, while chemotherapy treatment improved patient

23 survival. Their adjusted HRs were 1.71 (95\% CI: 1.08 - 2.71) for disease stage, 5.29 
1 (95\% CI: $2.50-11.20)$ for residual tumor size and 0.40 (95\% CI: $0.17-0.95)$ for

2 chemotherapy treatment, respectively. However, the associations of tumor grade,

3 histological type and patient age at surgery with the risk of death were not statistically

4 significant. Similarly to the Kaplan-Meier analysis, little evidence of association was

5 found between disease progression and $H I W I$ expression. Residual tumor size was

6 positively associated with the risk of relapse. The adjusted HR was 3.00 (95\% CI: 1.62

$7 \quad-5.57)$

8

9 Associations of HIWI expression with clinical and pathological features in epithelial

10 ovarian cancer

11 We also analyzed associations of $H I W I$ expression with clinical and pathologic

12 characteristics. A significant association was observed between HIWI expression and

13 patient response to chemotherapy $(\mathrm{p}=0.002)$. Patients with medium expression of

$14 \quad H I W I$ had worse response to chemotherapy than those with either low or high

15 expression. The odds ratio (OR) was 3.01 (95\% CI: $1.50-6.04)$ (Table 3). However, no

16 associations were found between HIWI expression and other clinical and pathologic

17 variables including disease stage, tumor grade, histological type, residual tumor size and

18 debulking results.

19

20 Interplay between HIWI and let-7a in epithelial ovarian cancer prognosis

21 The average EI of let-7a in this study was 4.62 with the range from 0.53 to $35.3\left(5^{\text {th }}-\right.$

$2295^{\text {th }}$ percentiles). 
1 Previous studies including immunoprecipitation sequencing results suggest that HIWI

2 might interplay with let-7a in regulating biological processes $[11,15,41,42]$. To examine

3 whether there is any interaction between HIWI and let-7a expressions in the patient

4 survival of epithelial ovarian cancer, we used the median of let-7a expression as the

5 cutoff value to classify let-7a into two groups, high (EI $\geq 4.62$, median) and low (EI <

6 4.62). Then we classified patients into four groups; group 1 with low $(E I=0)$ or high

7 (EI $\geq 0.32) H I W I$ and low $(\mathrm{EI}<4.62)$ let-7a, group 2 with low or high HIWI and high

8 let-7a $(\mathrm{EI} \geq 4.62$, median $)$, group 3 with medium $(0<\mathrm{EI}<0.32) H I W I$ and low let-7a,

9 and group 4 with medium HIWI and high let-7a. Multivariate Cox proportional hazard

10 models showed that the adjusted HRs of death were 1.11 (95\% CI: $0.66-1.86)$ for

11 Group 2, 1.64 (95\% CI: 0.88 - 3.04) for Group 3, and 2.71 (95\% CI: 1.38 - 5.32) for

12 Group 4 (Table 4) after the adjustment for patient age at surgery, disease stage, tumor

13 grade, residual tumor size, histological types and chemotherapy status. However, no

14 significant associations were found in progression-free survival in the multivariate 15 analysis.

17 We next sought to how HIWI and let-7a modulate each other the effect on patient

18 survival using stratification analyses (Table 5). When we stratified patients by HIWI

19 expression levels, we did not find the associations of let-7a expression with overall

20 survival $(\mathrm{p}>0.05)$ within the strata of either low/high or medium HIWI. In contrast,

21 when we stratified patients by let-7a expression levels (low and high), we found among

22 patients with high let-7a expression, medium expression of HIWI significantly

23 increased the risk of death compared to low/high HIWI expression; the adjusted HR was 
12.62 (95\% CI: $1.30-5.30)$. Among those with low let-7a expression, however, no

2 significant association was found between the risk of death and HIWI expression levels;

3 the adjusted HR was 1.63 (95\% CI: $0.86-3.08)$.

\section{Discussion}

5 This study examined the prognostic value of self-renewal-associated gene HIWI

6 expression. HIWI expression was detectable in 61\% (129 out of 211) epithelial ovarian

7 cancers, similar to the findings of two previous studies where 7 of 10 gastric cancer

8 patients and 40 of 56 pancreatic cancer patients showed detectable expression of $H I W I$

9 using RT-PCR, and 38 of 50 gastric cancers had positive immunohistochemical stains

10 for HIWI protein [20,23]._Moreover, Lim and colleagues reported that significantly

11 upregulated expression of HIWI gene was observed in epithelial ovarian cancer

12 compared to benign tumors [18]. The lack of association between HIWI expression and

13 clinical and pathologic variables in our study were in agreement with the investigations

14 of $H I W I$ in gastric cancer [20] and cervical cancer [46].

16 We also investigated the association of $H I W I$ expression in epithelial ovarian cancer

17 survival. We found that ovarian cancer patients with medium expression of HIWI had

18 shorter overall survival in comparison to those with low or high expression. This

19 association was independent of clinical or pathologic factors of the disease. We also

20 found that patients with medium levels of $H I W I$ expression had poor response to

21 chemotherapy compared to those with low or high expression. To our knowledge, this is

22 the first study to examine self-renewal-associated gene HIWI expression and survival of

23 patients with epithelial ovarian cancer in a clinical setting. Our study showed that 
1 patients with low or high HIWI expression had a more favorable prognosis. This finding

2 was similar to, but in the opposite direction of, observations of several previous clinical

3 studies, which showed that compared to medium, high or low HIWI expression was

4 associated with elevated death risks in patients with soft-tissue sarcoma and male

5 patients with pancreatic cancer [21-23]. Our result, however, seems to be more

6 consistent with findings of a very recent report, in which it was shown that significantly

7 increased HIWI expression was observed in epithelial ovarian cancer compared to

8 normal ovarian tissues and benign tumor tissues, while enforced overexpression of

9 HIWI repressed the invasiveness of ovarian cancer cell SKOV3 [18]. Our findings are

10 also supported by in vitro experiments that show similar impacts of loss- and gain-of-

11 function of $H I W I$ on cancer cells. Inhibition of $H I W I$ expression in gastric cancer cells

12 led to G2/M phase arrest and decreased proliferation index of the cancer cells [20],

13 while high HIWI expression appears to induce apoptosis in tumor cell lines of KG1

14 [15]. G2/M arrest is a critical step in the initiation of apoptosis [47-49]. Thus, both low

15 and high $H I W I$ expression may have similar effects on cancer cells.

17 Interestingly, previous studies on hepatocellular carcinoma [24], colorectal cancer [25]

18 and esophageal squamous carcinoma [27] have shown direct associations between high

19 HIWI proteins (immunohistochemical staining, IHC) and poor patient survival, but such

20 correlations have been limited to certain subgroups of patients. Zhao and colleagues

21 [24] reported that high HIWI protein was significantly associated with poor prognosis

22 of hepatocellular carcinoma only in patients with alpha-fetoprotein (AFP) less than 300

$23 \mathrm{ng} / \mathrm{ml}$, but not in those with AFP greater than that level. Zeng and colleagues [25] 
1 demonstrated that HIWI protein in tissues adjacent to tumor but not in primary tumor

2 was significantly associated with poor prognosis of colorectal carcinoma. Another study

3 [27] found that patients with high cytoplasmic but not nuclear HIWI protein had poor

4 prognosis in esophageal squamous carcinoma, while no association with prognosis was

5 seen if both cytoplasmic and nuclear HIWI proteins were combined for consideration.

6 Three possibilities may explain the discrepancy between our and previous studies on the

7 association of $H I W I$ expression with patient survival. First, translated HIWI from the

8 mRNAs may be aberrant due to premature stop codon-causing truncation or alternative

9 splicing, thereby influencing antigen determinants and IHC results, as well as its

10 function [18]. This aberrant expression of HIWI may result in the phenomenon that it is

11 high at mRNA levels but low at protein levels. Second, different laboratory methods

12 were applied to measure $H I W I$ expression (qPCR for mRNA vs IHC for protein); HIWI

13 expression at mRNA levels measured by qPCR showed biphasic effects, while HIWI

14 expression at protein levels by IHC had monotonic effects [24,25,27]. Finally, the

15 association between HIWI expression and cancer prognosis may be tumor or tissue

16 specific.

18 In this study, we also found a significant interaction between HIWI expression and let-

$197 \mathrm{a}$, increasing the risk of death in epithelial ovarian cancer. Stratification analyses

20 demonstrated let-7a modified the effect of $H I W I$ expression on overall survival of EOC.

21 Only at high let-7a levels did patients with medium HIWI expression increase the risk of

22 death. This finding supports and extends the previous observation reported by Chen

23 and colleagues [11], suggesting that HIWI protein not only physically binds let-7a, but 
1 also orchestrate each other, executing their biological functions. This also may help to

2 explain the finding that cytoplasmic but not nuclear HIWI positively associated with

3 poor prognosis of esophageal squamous carcinoma [27].

4 As expected, we found disease stage and residual tumor size, two well-established

5 prognostic risk factors, were unfavorable prognostic indicators, while chemotherapy

6 treatment improved survival. These results suggest that the findings in this study were

7 not observed by chance.

8

9 In summary, our study showed that self-renewal gene HIWI was associated with overall

10 survival as well as chemotherapy response in a U-shape correlation in epithelial ovarian

11 cancer. Taken together with the recent findings reported by Lim and colleagues [18],

12 HIWI expression at a moderate level may associate with the increased risk of death and

13 poor chemotherapy response in epithelial ovarian cancer. We also found the synergetic

14 effect of self-renewal gene HIWI and miRNA let-7a on patient survival of epithelial

15 ovarian cancer. These findings suggest that the interplay between self-renewal gene

$16 H I W I$ and miRNA let-7a has significant clinical relevance in epithelial ovarian cancer

17 prognosis, and reveal a potential strategy by the modulation of HIWI and let-7a in the

18 management of epithelial ovarian cancer.

19

20 Conflict of Interest Statement

21 The authors declare that they have no conflict of interest. 
References

3 1. Qiao D, Zeeman AM, Deng W, Looijenga LH, Lin H. Molecular

4 characterization of hiwi, a human member of the piwi gene family whose

5 overexpression is correlated to seminomas. Oncogene 2002;21(25):3988-3999.

6 2. Cerutti L, Mian N, Bateman A. Domains in gene silencing and cell

7 differentiation proteins: the novel PAZ domain and redefinition of the Piwi

8 domain. Trends Biochem Sci 2000;25(10):481-482.

93 . Peters L, Meister G. Argonaute proteins: mediators of RNA silencing. Mol Cell

10 2007;26(5):611-623.

4. Farazi TA, Juranek SA, Tuschl T. The growing catalog of small RNAs and their association with distinct Argonaute/Piwi family members. Development

5. Tolia NH, Joshua-Tor L. Slicer and the argonautes. Nat Chem Biol 2007;3(1):36-43.

6. Meister G. Argonaute proteins: functional insights and emerging roles. Nat Rev Genet 2013;14(7):447-459.

7. Samji T. PIWI, piRNAs, and germline stem cells: what's the link? Yale J Biol Med 2009;82(3):121-124.

8. Siddiqi S, Terry M, Matushansky I. Hiwi mediated tumorigenesis is associated with DNA hypermethylation. PLoS One 2012;7(3):e33711.

9. Brennecke J, Aravin AA, Stark A et al. Discrete small RNA-generating loci as master regulators of transposon activity in Drosophila. Cell 2007;128(6):10891103.

10. Li C, Vagin VV, Lee $\mathrm{S}$ et al. Collapse of germline piRNAs in the absence of Argonaute3 reveals somatic piRNAs in flies. Cell 2009;137(3):509-521.

11. Chen R, Chang G, Zhang Y et al. Cloning of the quail PIWI gene and characterization of PIWI binding to small RNAs. PLoS One 2012;7(12):e51724.

12. Tahbaz N, Kolb FA, Zhang H, Jaronczyk K, Filipowicz W, Hobman TC. Characterization of the interactions between mammalian PAZ PIWI domain proteins and Dicer. EMBO Rep 2004;5(2):189-194.

13. Kolb FA, Zhang H, Jaronczyk K, Tahbaz N, Hobman TC, Filipowicz W. Human dicer: purification, properties, and interaction with PAZ PIWI domain proteins. Methods Enzymol 2005;392:316-336.

14. Megosh HB, Cox DN, Campbell C, Lin H. The role of PIWI and the miRNA machinery in Drosophila germline determination. Curr Biol 2006;16(19):18841894.

15. Sharma AK, Nelson MC, Brandt JE et al. Human CD34(+) stem cells express the hiwi gene, a human homologue of the Drosophila gene piwi. Blood 2001;97(2):426-434.

16. Ross RJ, Weiner MM, Lin H. PIWI proteins and PIWI-interacting RNAs in the soma. Nature 2014;505(7483):353-359. 
17. Cox DN, Chao A, Lin H. piwi encodes a nucleoplasmic factor whose activity modulates the number and division rate of germline stem cells. Development 2000;127(3):503-514.

18. Lim SL, Ricciardelli C, Oehler MK, De Arao Tan IM, Russell D, Grutzner F. Overexpression of piRNA Pathway Genes in Epithelial Ovarian Cancer. PLoS One 2014;9(6):e99687.

19. Suzuki R, Honda S, Kirino Y. PIWI Expression and Function in Cancer. Front Genet 2012;3:204.

20. Liu X, Sun Y, Guo J et al. Expression of hiwi gene in human gastric cancer was associated with proliferation of cancer cells. Int J Cancer 2006;118(8):19221929.

21. Taubert H, Greither T, Kaushal D et al. Expression of the stem cell self-renewal gene Hiwi and risk of tumour-related death in patients with soft-tissue sarcoma. Oncogene 2007;26(7):1098-1100.

22. Taubert H, Wurl P, Greither T et al. Stem cell-associated genes are extremely poor prognostic factors for soft-tissue sarcoma patients. Oncogene 2007;26(50):7170-7174.

23. Grochola LF, Greither T, Taubert $\mathrm{H}$ et al. The stem cell-associated Hiwi gene in human adenocarcinoma of the pancreas: expression and risk of tumour-related death. Br J Cancer 2008;99(7):1083-1088.

24. Zhao YM, Zhou JM, Wang LR et al. HIWI is associated with prognosis in patients with hepatocellular carcinoma after curative resection. Cancer 2012;118(10):2708-2717.

25. Zeng Y, Qu LK, Meng L et al. HIWI expression profile in cancer cells and its prognostic value for patients with colorectal cancer. Chin Med J (Engl) 2011;124(14):2144-2149.

26. Sun G, Wang Y, Sun L et al. Clinical significance of Hiwi gene expression in gliomas. Brain Res 2011;1373:183-188.

27. He W, Wang Z, Wang Q et al. Expression of HIWI in human esophageal squamous cell carcinoma is significantly associated with poorer prognosis. BMC Cancer 2009;9:426.

28. Johnson SM, Grosshans H, Shingara $\mathrm{J}$ et al. RAS is regulated by the let-7 microRNA family. Cell 2005;120(5):635-647.

29. Johnson CD, Esquela-Kerscher A, Stefani G et al. The let-7 MicroRNA Represses Cell Proliferation Pathways in Human Cells. Cancer Res 2007;67(16):7713-7722.

30. Zhu H, Shyh-Chang N, Segre AV et al. The Lin28/let-7 axis regulates glucose metabolism. Cell 2011;147(1):81-94.

31. Erturk E, Cecener G, Egeli U et al. Expression status of let-7a and miR-335 among breast tumors in patients with and without germ-line BRCA mutations. Mol Cell Biochem 2014;395(1-2):77-88.

32. Yanaihara N, Caplen N, Bowman E et al. Unique microRNA molecular profiles in lung cancer diagnosis and prognosis. Cancer Cell 2006;9(3):189-198.

33. Akao Y, Nakagawa Y, Naoe T. let-7 microRNA functions as a potential growth suppressor in human colon cancer cells. Biol Pharm Bull 2006;29(5):903-906. 
34. Muller DW, Bosserhoff AK. Integrin beta 3 expression is regulated by let-7a miRNA in malignant melanoma. Oncogene 2008;27(52):6698-6706.

35. Xie YL, Yang YJ, Tang $C$ et al. Estrogen combined with progesterone decreases cell proliferation and inhibits the expression of Bcl-2 via microRNA let-7a and miR-34b in ovarian cancer cells. Clin Transl Oncol 2014.

36. Ruzzo A, Graziano F, Vincenzi B et al. High let-7a microRNA levels in KRASmutated colorectal carcinomas may rescue anti-EGFR therapy effects in patients with chemotherapy-refractory metastatic disease. Oncologist 2012;17(6):823829.

37. Lu L, Schwartz P, Scarampi L et al. MicroRNA let-7a: a potential marker for selection of paclitaxel in ovarian cancer management. Gynecol Oncol 2011;122(2):366-371.

38. Golestaneh AF, Atashi A, Langroudi L, Shafiee A, Ghaemi N, Soleimani M. miRNAs expressed differently in cancer stem cells and cancer cells of human gastric cancer cell line MKN-45. Cell Biochem Funct 2012;30(5):411-418.

39. Liu Y, Li H, Feng J et al. Lin28 induces epithelial-to-mesenchymal transition and stemness via downregulation of let-7a in breast cancer cells. PLoS One 2013;8(12):e83083.

40. Cairo S, Wang Y, de Reynies A et al. Stem cell-like micro-RNA signature driven by Myc in aggressive liver cancer. Proc Natl Acad Sci U S A 2010;107(47):20471-20476.

41. Tokumaru S, Suzuki M, Yamada H, Nagino M, Takahashi T. let-7 regulates Dicer expression and constitutes a negative feedback loop. Carcinogenesis 2008;29(11):2073-2077.

42. Worringer KA, Rand TA, Hayashi Y et al. The let-7/LIN-41 pathway regulates reprogramming to human induced pluripotent stem cells by controlling expression of prodifferentiation genes. Cell Stem Cell 2014;14(1):40-52.

43. Shepherd JH. Revised FIGO staging for gynaecological cancer. Br J Obstet Gynaecol 1989;96(8):889-892.

44. Scully R, Sobin L, Serov S. Histological typing of ovarian tumors. Berlin (NY): Springer; 1999.

45. Lu L, Katsaros D, de la Longrais IA, Sochirca O, Yu H. Hypermethylation of let-7a-3 in epithelial ovarian cancer is associated with low insulin-like growth factor-II expression and favorable prognosis. Cancer Res 2007;67(21):1011710122.

46. Liu WK, Jiang XY, Zhang ZX. Expression of PSCA, PIWIL1 and TBX2 and its correlation with HPV16 infection in formalin-fixed, paraffin-embedded cervical squamous cell carcinoma specimens. Arch Virol 2010;155(5):657-663.

47. Concin N, Stimpfl M, Zeillinger C et al. Role of p53 in G2/M cell cycle arrest and apoptosis in response to gamma-irradiation in ovarian carcinoma cell lines. Int J Oncol 2003;22(1):51-57.

48. Manna SK, Bose JS, Gangan V et al. Novel derivative of benzofuran induces cell death mostly by G2/M cell cycle arrest through p53-dependent pathway but partially by inhibition of NF-kappaB. J Biol Chem 2010;285(29):22318-22327. 
49. Zhang Z, Miao L, Lv C et al. Wentilactone B induces G2/M phase arrest and apoptosis via the Ras/Raf/MAPK signaling pathway in human hepatoma SMMC-7721 cells. Cell Death Dis 2013;4:e657.

\section{Figure legends}

Figure 1. Kaplan-Meier overall survival curves by levels of HIWI expression in

14 epithelial ovarian cancer. Patients with either low $(\mathrm{EI}=0)$ or high $(\mathrm{EI} \geq 0.32) H I W I$

15 expression had better overall survivals than those with medium $(0<\mathrm{EI}<0.32)$

16 expression $(\mathrm{p}=0.025, \log$-rank test $)$

17

18

19

20

21

22

23

24

25

26

27

28

29 
4 Table 1 Clinicopathological variables and expressions of HIWI and let-7a in 211 epithelial ovarian cancer patients

\begin{tabular}{|c|c|c|}
\hline \multicolumn{3}{|l|}{ Variables } \\
\hline Total & 211 & 100 \\
\hline \multicolumn{3}{|l|}{ Disease Stage } \\
\hline $\mathrm{I}$ & 52 & 24.6 \\
\hline II & 12 & 5.7 \\
\hline III & 133 & 63.0 \\
\hline IV & 14 & 6.6 \\
\hline \multicolumn{3}{|l|}{ Tumor Grade } \\
\hline$\overline{1}$ & 34 & 16.1 \\
\hline 2 & 40 & 19.0 \\
\hline 3 & 137 & 64.9 \\
\hline \multicolumn{3}{|l|}{ Histology $(n=178)$} \\
\hline Clear Cell & 16 & 7.6 \\
\hline Endometrial & 41 & 19.4 \\
\hline Mucinous & 18 & 8.5 \\
\hline Müllerian & 14 & 6.6 \\
\hline Undifferentiated & 36 & 17.1 \\
\hline Other & 1 & 0.5 \\
\hline Sub-total (Non-serous) & 126 & 59.7 \\
\hline$\overline{\text { Serous }}$ & 85 & 40.3 \\
\hline \multicolumn{3}{|l|}{ Debulking Results } \\
\hline Optimal & 108 & 51.9 \\
\hline Suboptimal & 100 & 48.1 \\
\hline \multicolumn{3}{|l|}{ Residual Tumor Size (cm) } \\
\hline 0 & 91 & 44.0 \\
\hline \multirow[t]{2}{*}{$>0$} & 116 & 56.0 \\
\hline & $\mathrm{N}$ & Median (range) \\
\hline Age (years) & 208 & $58(26-82)$ \\
\hline$H I W I$ expression & 211 & $0.06(0-14.28)$ \\
\hline Let-7a expression & 211 & $4.62(0-655)$ \\
\hline
\end{tabular}

6

7 
2

3

4

5

6

7

8

9

10

11

12

13

Table 2. Associations of HIWI expression and patient survival in epithelial ovarian

\begin{tabular}{llc}
\hline Variable & Relapse & Death \\
\cline { 2 - 3 } & $\mathrm{HR}^{1}\left(95 \% \mathrm{CI}^{2}\right)$ & $\mathrm{HR}(95 \% \mathrm{CI})$ \\
\hline
\end{tabular}

$\underline{\text { Univariate }}$

HIWI (Medium vs. Low or $1.33(0.863-2.05)$

$1.63(1.06-2.52)$

High)

$\underline{\text { Multivariate }^{3}}$

HIWI (Medium vs. Low or $1.38(0.88-2.16)$

$1.89(1.29-2.98)$

High)

Age

$1.02(0.99-1.04)$

$1.01(0.99-1.03)$

Disease stage

$1.28(0.88-1.87)$

$1.71(1.08-2.71)$

Tumor grade

$1.28(0.89-1.84)$

$1.45(0.97-2.17)$

Residual tumor size ( $>0$ vs 0 )

$3.00(1.62-5.57)$

$5.29(2.50-11.20)$

Histological type (Serous vs

$1.17(0.75-1.82)$

$0.73(0.46-1.13)$

non-serous)

Chemotherapy (yes vs no)

$1.86(0.55-6.24)$

$0.40(0.17-0.95)$

$14 \quad$ 1. HR: Hazards Ratio.

15 2. CI: Confidence Interval.

16 3. Adjusted for age at surgery, disease stage, tumor grade, residual tumor size,

17 histological type and chemotherapy status.

18

19 
3 Table 3. Associations of HIWI expression with clinical and pathologic variables in

4 epithelial ovarian cancer

\begin{tabular}{|c|c|c|c|c|c|}
\hline Variable & $\mathrm{N}$ & $\begin{array}{c}\text { Low/ High } H I W I^{1} \\
\mathrm{n}(\%)\end{array}$ & $\begin{array}{c}\text { Medium } H I W I \\
\mathrm{n}(\%)\end{array}$ & $\mathrm{OR}^{2}\left(95 \% \mathrm{CI}^{3}\right)$ & $\mathrm{p}$ value \\
\hline Disease Stage & & & & $0.79(0.42-1.48)^{4}$ & 0.459 \\
\hline $1-2$ & 64 & $42(65.6)$ & $22(34.4)$ & & \\
\hline $3-4$ & 147 & $104(70.8)$ & $43(29.2)$ & & \\
\hline$\underline{\text { Tumor Grade }}$ & & & & $1.32(0.71-2.47)$ & 0.382 \\
\hline $1-2$ & 74 & $54(73.0)$ & $20(27.0)$ & & \\
\hline 3 & 137 & $92(67.2)$ & $45(32.8)$ & & \\
\hline$\underline{\text { Residual Size }(\mathrm{cm})}$ & & & & $1.01(0.56-1.83)$ & 0.967 \\
\hline 0 & 91 & $63(69.2)$ & $28(30.8)$ & & \\
\hline$>0$ & 116 & $80(69.0)$ & $36(31.0)$ & & \\
\hline$\underline{\text { Histological Type }}$ & & & & $1.42(0.79-2.56)$ & 0.246 \\
\hline Non-serous & 126 & $91(72.2)$ & $35(27.8)$ & & \\
\hline Serous & 85 & $55(64.7)$ & $30(35.3)$ & & \\
\hline$\underline{\text { Debulking Result }}$ & & & & $0.82(0.45-1.47)$ & 0.502 \\
\hline Sub-optimal & 100 & $67(67.0)$ & $33(33.0)$ & & \\
\hline Optimal & 108 & $77(71.3)$ & $31(28.7)$ & & \\
\hline Chemotherapy Response & & & & 3.01 (1.50-6.04) & 0.002 \\
\hline Yes & 128 & $98(76.6)$ & $30(23.4)$ & & \\
\hline No & 48 & $25(52.1)$ & $23(47.9)$ & & \\
\hline
\end{tabular}

5 1. HIWI expression: low, EI = 0 (undetectable); medium, $0<\mathrm{EI}<0.32$; high, EI $6 \geq 0.32$.

7 2. OR: odds ratio obtained from logistic regression analysis

8 3. CI: confidential interval.

9 4. In logistic regression analyses, the group of low or high HIWI expression was

10 chosen as reference, and the second level of each variable as 'event'.

11

12 
2

3

4

5

6

7

8

9

10

11 ovarian cancer

Table 4. Interaction of HIWI and let-7a expression in patient survival of epithelial

\begin{tabular}{|c|c|c|c|c|c|c|}
\hline \multirow[t]{2}{*}{ Groups $^{1}$} & \multirow[t]{2}{*}{$H I W I$} & \multirow[t]{2}{*}{ Let-7a } & \multicolumn{2}{|c|}{ Relapse } & \multicolumn{2}{|c|}{ Death } \\
\hline & & & Adj-HR ${ }^{2}$ & $95 \% \mathrm{CI}^{3}$ & Adj-HR & $95 \% \mathrm{CI}$ \\
\hline Group 1 & Low/high & Low & 1.00 & & 1.00 & \\
\hline Group 2 & Low/high & High & 0.94 & $0.57-1.53$ & 1.11 & $0.66-1.86$ \\
\hline Group 3 & Medium & Low & 1.26 & $0.70-2.29$ & 1.64 & $0.88-3.04$ \\
\hline Group 4 & Medium & High & 1.45 & $0.74-2.85$ & 2.71 & $1.38-5.32$ \\
\hline
\end{tabular}

1. Groups: group 1 , low $(\mathrm{EI}=0)$ or high $(\mathrm{EI} \geq 0.32) H I W I$ and low $(\mathrm{EI}<4.62)$ let$7 a$; group 2, low or high $H I W I$ and high let-7a (EI $\geq 4.62)$; group 3, medium $(0<$ EI <0.32) HIWI and low let-7a; and group 4, medium HIWI and high let-7a.

2. Adj-HR: adjusted Hazard Ratio for patient age at surgery, disease stage, tumor grade, residual tumor size, histological type and chemotherapy status.

3. CI: Confidence Interval. 
Table 5. Stratification analyses for the associations of $\mathrm{HIWI}$ and let-7a expression with patient survival in epithelial ovarian cancer

\begin{tabular}{lllll}
\hline Stratified & Comparison Variable & \multicolumn{3}{c}{ Death } \\
\cline { 3 - 4 } Variable $^{1}$ & & Adj-HR ${ }^{2}$ & $95 \%$ CI $^{3}$ & P value \\
\hline HIWI & Let-7a & 1.19 & $0.71-2.01$ & 0.511 \\
Low/high & High vs. low & 1.61 & $0.75-3.43$ & 0.218 \\
Medium & High vs. low & & & \\
Let-7a & HIWI & 1.63 & $0.86-3.08$ & 0.137 \\
Low & Medium vs. low/high & $\mathbf{2 . 6 2}$ & $\mathbf{1 . 3 0}-\mathbf{5 . 3 0}$ & $\mathbf{0 . 0 0 7}$ \\
High & Medium vs low/high & $\mathbf{2 0 0}$ & \\
\hline
\end{tabular}

1. HIWI: low (EI $=0$, undetectable), medium $(0<\mathrm{EI}<0.32)$, high $(\mathrm{EI} \geq 0.32)$; let-7a: low (EI < 4.62), high (EI $\geq 4.62)$.

2. Adj-HR: adjusted Hazard Ratio for patient age at surgery, disease stage, tumor grade, residual tumor size, histological type and chemotherapy status.

3. CI: Confidence Interval. 
1

2

3

4

5

6

7

8

9

10

11

12

13

14

15

16

Figure 1. Kaplan-Meier overall survival curves by levels of HIWI expression

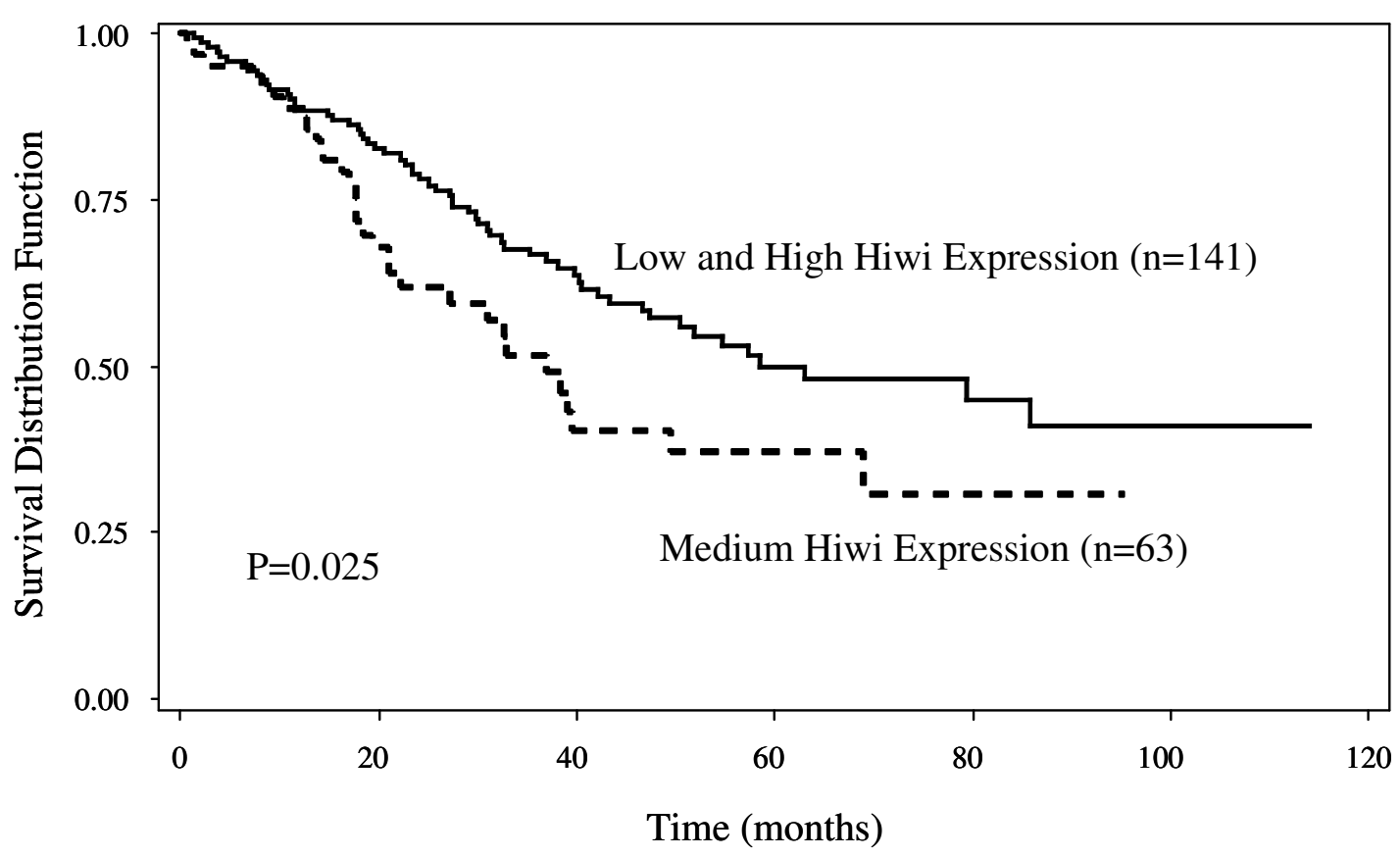

